\title{
Double endoscopic bypass for gastric outlet obstruction and biliary obstruction $\square$
}

\section{다 $(9)$}

\author{
Authors \\ Olaya I. Brewer Gutierrez ${ }^{1}$, Jose Nieto², Shayan Irani ${ }^{3}$, Theodore James ${ }^{4}$, Renata Pieratti Bueno ${ }^{1}$, Yen-I Chen ${ }^{1}$, Majidah \\ Bukhari ${ }^{1}$, Omid Sanaei ${ }^{1}$, Vivek Kumbhari ${ }^{1}$, Vikesh K. Singh ${ }^{1}$, Saowanee Ngamruengphong ${ }^{1}$, Todd H. Baron ${ }^{4}$, Mouen A. \\ Khashab ${ }^{1}$
}

\section{Institutions}

1 Division of Gastroenterology and Hepatology, Johns Hopkins Medical Institutions, Baltimore, Maryland, United States

2 Borland-Groover Clinic, Jacksonville, Florida, United States

3 Division of Gastroenterology and Hepatology, Virginia Mason Hospital, Seattle, Washington, United States

4 Division of Gastroenterology and Hepatology, University of North Carolina, Chapel Hill, North Carolina, United States

submitted 22.4.2017

accepted after revision 23.6.2017

Bibliography

DOI https://doi.org/10.1055/s-0043-115386 |

Endoscopy International Open 2017; 05: E893-E899

(c) Georg Thieme Verlag KG Stuttgart · New York

ISSN 2364-3722

Corresponding author

Mouen A. Khashab, MD, Johns Hopkins Hospital, 1800

Orleans Street, Sheikh Zayed Tower, Baltimore, MD 21287

Fax: 443-287-1960

mkhasha1@jhmi.edu

\section{ABSTRACT}

Background and study aims Double endoscopic bypass entails EUS-guided gastroenterostomy (EUS-GE) and EUSguided biliary drainage (EUS-BD) in patients who present with gastric outlet and biliary obstruction. We report a multicenter experience with double endoscopic bypass.

Patients and methods Retrospective, multicenter series involving 3 US centers. Patients who underwent double endoscopic bypass for malignant gastric and biliary obstruction from $1 / 2015$ to $12 / 2016$ were included. Primary outcome was clinical success defined as tolerance of oral intake and resolution of cholestasis. Secondary outcomes included technical success, re-interventions and adverse events (AE).

Results Seven patients with pancreatic head cancer $(57.1 \%$ females; mean age $64.6 \pm 12.5$ years) underwent double endoscopic bypass. Four patients had EUS-GE and EUS-BD performed during the same session with a mean procedure time of $70 \pm 20.4$ minutes. EUS-GE and EUS-BD were technically successful in all patients, all of whom were able to tolerate oral intake with resolution of cholestasis in 6 (87.5\%). One patient had a repeat EUS-BD with normalization of bilirubin. There were no adverse events.

Conclusions Double endoscopic bypass is feasible and effective when performed by experienced operators. Studies comparing this novel concept to existing techniques are warranted.

\section{Introduction}

Patients with periampullary malignancies may present concomitantly with gastric outlet obstruction (GOO) and biliary obstruction [1]. Biliary obstruction may also manifest before or after luminal obstruction. Standard access to the biliary tree with ERCP in any of these patients is hampered by malignant luminal compromise [1]. With the recent advent of interventional EUS and dedicated accessories, EUS-guided management of both $\mathrm{GOO}$ and biliary obstruction is now possible [3].

EUS-guided gastroenterostomy (EUS-GE) entails placing a lumen-apposing metallic stent (LAMS) between the stomach and a small bowel loop distal to the site of obstruction, thereby bypassing the tumor site [4-6]. EUS-guided biliary drainage has been described in patients with GOO. This is most frequently accomplished via either hepatogastrostomy (HGS) or choledochoduodenostomy (CDS) techniques depending on the exact site of obstruction [7].

The concept of double endoscopic bypass can now be applied to patients with periampullary malignancies who present with GOO and biliary obstruction. EUS-GE and EUS-BD can be performed during the same session or on separate occasions depending on patient presentation and endoscopist's preference. This concept was previously described by Khashab and 
colleagues when they reported double endoscopic bypass in a 70-year-old female with unresectable head-of-pancreas cancer with distal biliary obstruction and GOO [8]. Herein we report a multicenter series with performance of double endoscopic bypass in patients with malignant gastric outlet obstruction and biliary obstruction.

\section{Patients and methods}

This was a multicenter, retrospective case series from January 2015 to December 2016 at 3 US tertiary centers. Inclusion criteria were patients with primary or metastatic malignancies involving the gastrointestinal tract who had symptomatic gastric outlet obstruction confirmed on endoscopy, and who underwent EUS-GE. Only patients who previously, concomitantly or subsequently presented with malignant biliary obstruction and underwent EUS-BD were included. Therefore, the study cohort included consecutive patients who underwent double endoscopic bypass for malignant GOO and biliary obstruction. Institutional Review Board for retrospective studies involving EUSGE and EUS-BD was obtained in each institution.

\section{Outcomes and definitions}

The primary outcome was rate of clinical success defined as 1) the ability to tolerate oral intake (at least soft solids) without vomiting and 2) resolution of cholestasis. Food intake was measured by the standardized GOO Scoring System (GOOSS) score: $0=$ no oral intake, 1 = liquids only, 2 =soft solids, $3=$ almost complete diet, and 4 = full diet [9].

Secondary outcomes included technical success defined as adequate positioning and deployment of the stents as determined endoscopically and radiographically; re-intervention (endoscopic, radiologic or surgical) either for recurrent or persistent symptoms of GOO or biliary obstruction; procedure related adverse events (AEs) defined as any adverse event within 30 days of the procedure deemed to be secondary to the index endoscopic procedure; severity of AEs as grade per the ASGE lexicon [10].

\section{EUS-GE technique}

All patients received intravenous antibiotics immediately prior the procedure and general anesthesia with endotracheal intubation. EUS-GE was performed using the direct access technique or balloon-assisted approach as previously described [4, $5,11]$. Briefly, the direct access approach entails initial filling of the proximal small bowel with fluid (saline, contrast, and/or methylene blue), followed by direct puncture of a small bowel loop adjacent to the gastric wall using cautery-tip LAMS) ( $\vee$ Fig.1, $\vee$ Video1). The balloon-assisted technique starts with the insertion of a guidewire across the obstruction deep into the small bowel. A stone retrieval or dilating balloon is then advanced over the wire across the obstruction. Following inflation of the balloon with contrast fluid, EUS-guided puncture of the balloon is performed transgastrically with a 19gauge needle. Bursting of the balloon confirms the correct location of the puncture within the small bowel. A guidewire is then advanced into the balloon serving as a tract for GE tract dilation and LAMS insertion ( $>$ Fig. 2 ).

\section{EUS-BD technique}

EUS-BD was performed as previously described [7,12]. EUSCDS was performed preferentially whenever feasible. EUS-CDS is not possible when there is significant tumor burden in the duodenal bulb. In these cases, EUS-HGS was performed. EUSguided gallbladder drainage (EUS-GBD) was performed as the EUS-BD technique of choice when the above alternative techniques were not possible or failed ( $\triangleright$ Fig. 3, $\triangleright$ Video 1 ).

\section{Results}

During the study period, 7 patients underwent double endoscopic bypass for malignant GOO and biliary obstruction ( $\triangleright \mathrm{Ta}$ ble 1 ). The mean age of patients was $64.6 \pm 12.5$ years and 4 (57.1\%) were females. All patients had pancreatic cancer. Site of luminal obstruction was in proximal duodenum in all patients. In all cases, patients presented simultaneously with both GOO and biliary obstruction. The mean pre-procedural bilirubin was $7.7 \pm 5.1 \mathrm{mg} / \mathrm{dL}$ and mean alkaline phosphatase was $319 \pm 150.4 \mathrm{U} / \mathrm{l}$. Out of the seven patients, only one had a previous ERCP with CBD SEMS placement 95 days prior to the GOO and biliary obstruction. Double endoscopic bypass, with both EUS-GE and EUS-BD performed during same endoscopy session, was carried in 4 patients. In the remaining 3 patients, EUS-GE and EUS-BD were done in separate sessions at the discretion of the endoscopist, with a mean of $3.3 \pm 2.5$ days between the two procedures. The mean procedure time was $70 \pm$ 20.4 minutes in those cases where the EUS-GE and EUS-BD were done simultaneously.

EUS-GE was successful (technical success) in all 7 (100\%) patients. Direct access technique was used in 5 patients, while the balloon-assisted technique was used in the remaining 2 patients. All patients underwent placement of the 15-mm LAMS (non-cautery enhanced in 2 and cautery enhanced in 5; Axios stent, Boston Scientific, Natick, MA). There were no AEs. Clinical success was achieved in $7(100 \%)$ patients. A total of 3 patients tolerated soft solids and 4 full diet. Recurrent GOO did not occur in any of the 7 patients during a median follow-up period of 106 days [IQR: 66 - 235] (> Table 2).

EUS-BD was successful (technical success) in all (100\%) patients. The most common EUS-BD technique used was EUSGBD in $4(57.1 \%)$ patients, followed by EUS-CDS in $2(28.6 \%)$ and EUS- HGS in 1(14.3\%). Reasons for EUS-GBD as the technique of choice for biliary drainage were unsafe window to perform the CDS or HGS in 2 patients, due to artery interposition between the transducer and the CBD; previous metallic stent in the CBD that precluded EUS-CDS and non-intrahepatic duct dilation precluding EUS-HGS in 1 patient, and multiple liver metastasis in 1 patient, for which EUS-HGS was not possible and CBD was non-dilated. Most patients $(n=4,42.9 \%)$ underwent placement of the $10-\mathrm{mm}$ LAMS (non-cautery enhanced in 1 and cautery enhanced in 3; Axios stent, Boston Scientific) followed by 2 patients who had the 15-mm LAMS (cautery enhanced; Axios stent, Boston Scientific). One patient had place- 

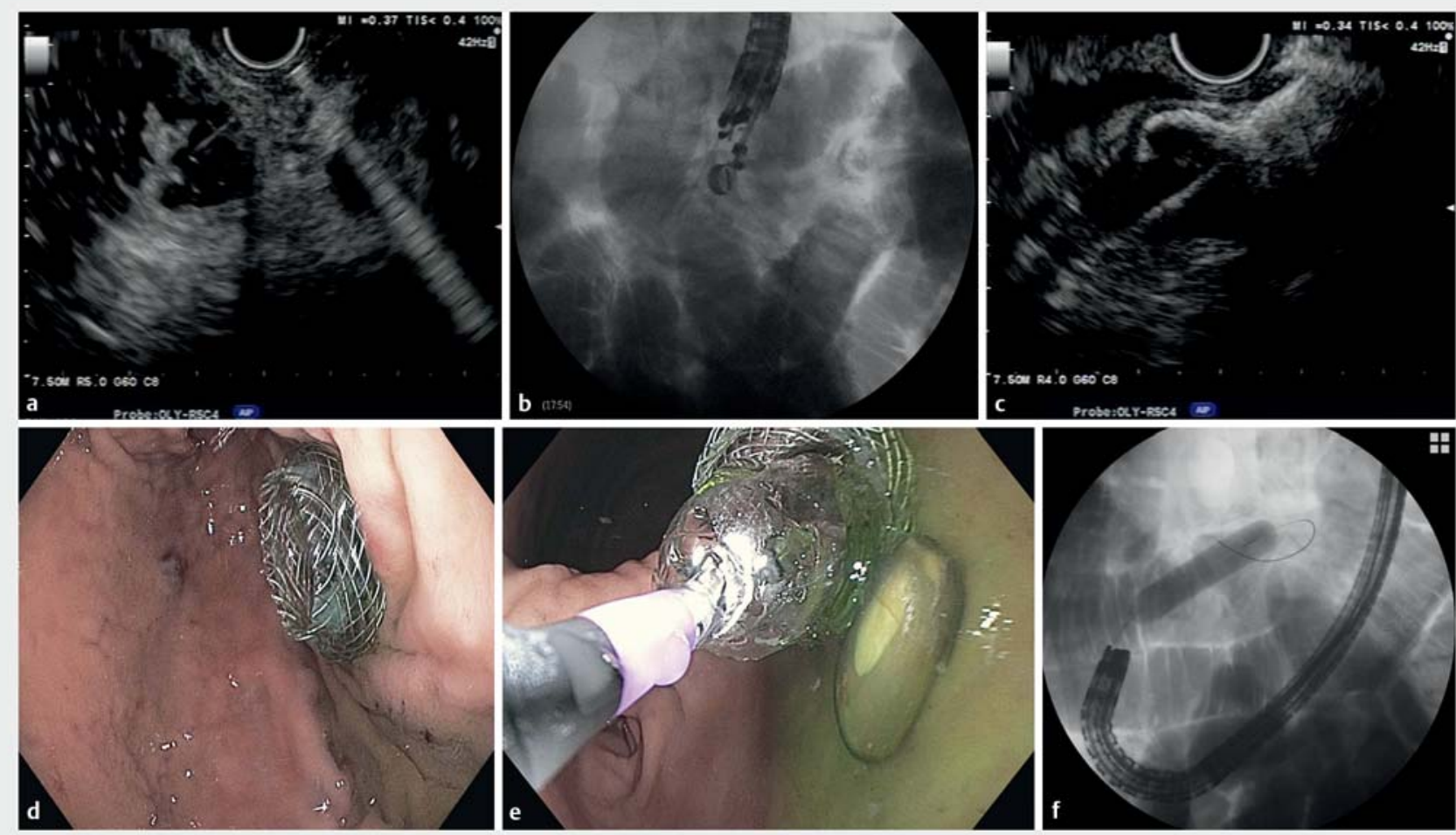

- Fig. 1 EUS-G] using the direct technique in a 70-year-old patient with malignant GOO and biliary obstruction secondary to pancreatic head adenocarcinoma. A diagnostic EGD scope is advanced into the duodenum and the small bowel is filled with contrast, saline and methylene blue. A linear echoendoscope is advanced into the stomach. a The small bowel lumen previously filled with contrast, saline and methylene blue is visualized transgastrically with EUS and punctured with a 19-gauge FNA needle. b Fluoroscopy showing the EUS scope and the 19-gauge needle in the small bowel loop. c Distal flange of a cautery-enhanced LAMS deployed in the small bowel loop. $\mathbf{d}$ Endoscopic view of a fully deployed cautery-enhanced LAMS. e Stent lumen dilation with a $15 \mathrm{~mm}$ balloon. $\mathbf{f}$ Fluoroscopy showing balloon dilation of the LAMS.

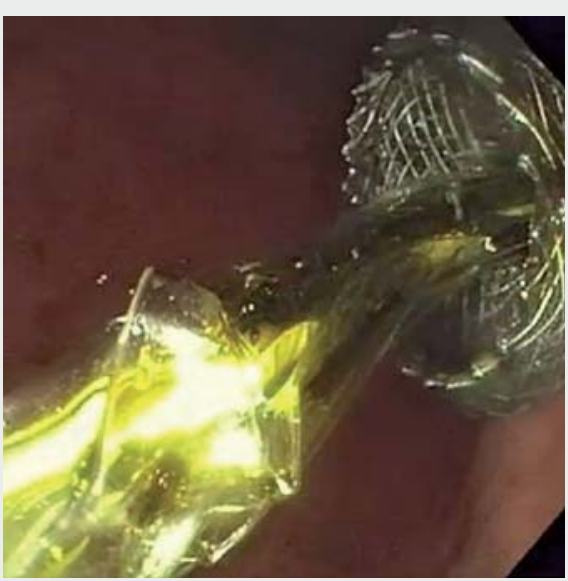

$\triangle$ Video 1 A 70-year-old patient with malignant GOO and biliary obstruction secondary to pancreatic head adenocarcinoma. Double endoscopic bypass with EUS-guided GJ using the direct technique and EUS-GBD performed during the same session. ment of a 10-mm fully-covered self-expandable metallic biliary stent (FCSEMS) (Wallflex, Boston Scientific). There were no AE. One patient had intra-procedural bleeding during dilation of the LAMS. This was successfully treated with balloon tamponade for 20 minutes. Clinical success was initially achieved in 6 (85.7\%) patients with a mean post-procedural bilirubin of $1.9 \pm$ $1.6 \mathrm{mg} / \mathrm{dl}$ and mean alkaline phosphatase of $286.7 \pm 286.7 \mathrm{U} / \mathrm{l}$. Cholestasis did not resolve in one patient after EUS-GBD and 4 days after the index procedure had an EGD with a cholangiogram through the cholecystogastrostomy that showed cystic duct obstruction. An EUS-HGS was then performed with placement of a $10 \mathrm{~mm} \times 80 \mathrm{~mm}$ FCSEMS (Wallflex, Boston Scientific). Clinical success with normalization of bilirubin was then achieved. Another patient developed fever 3 days after the EUS-CDS in which a $10 \times 10 \mathrm{~mm}$ LAMS was placed. The LAMS was not patent due to collapse of the previously dilated bile duct. A $10 \times 40 \mathrm{~mm}$ FCSEMS was placed across the LAMS with resolution of fever and cholestasis. Recurrent biliary obstruction did not occur in any of the patients during a median follow-up period of 106 days [IQR: 67 - 229] ( Table 3). 

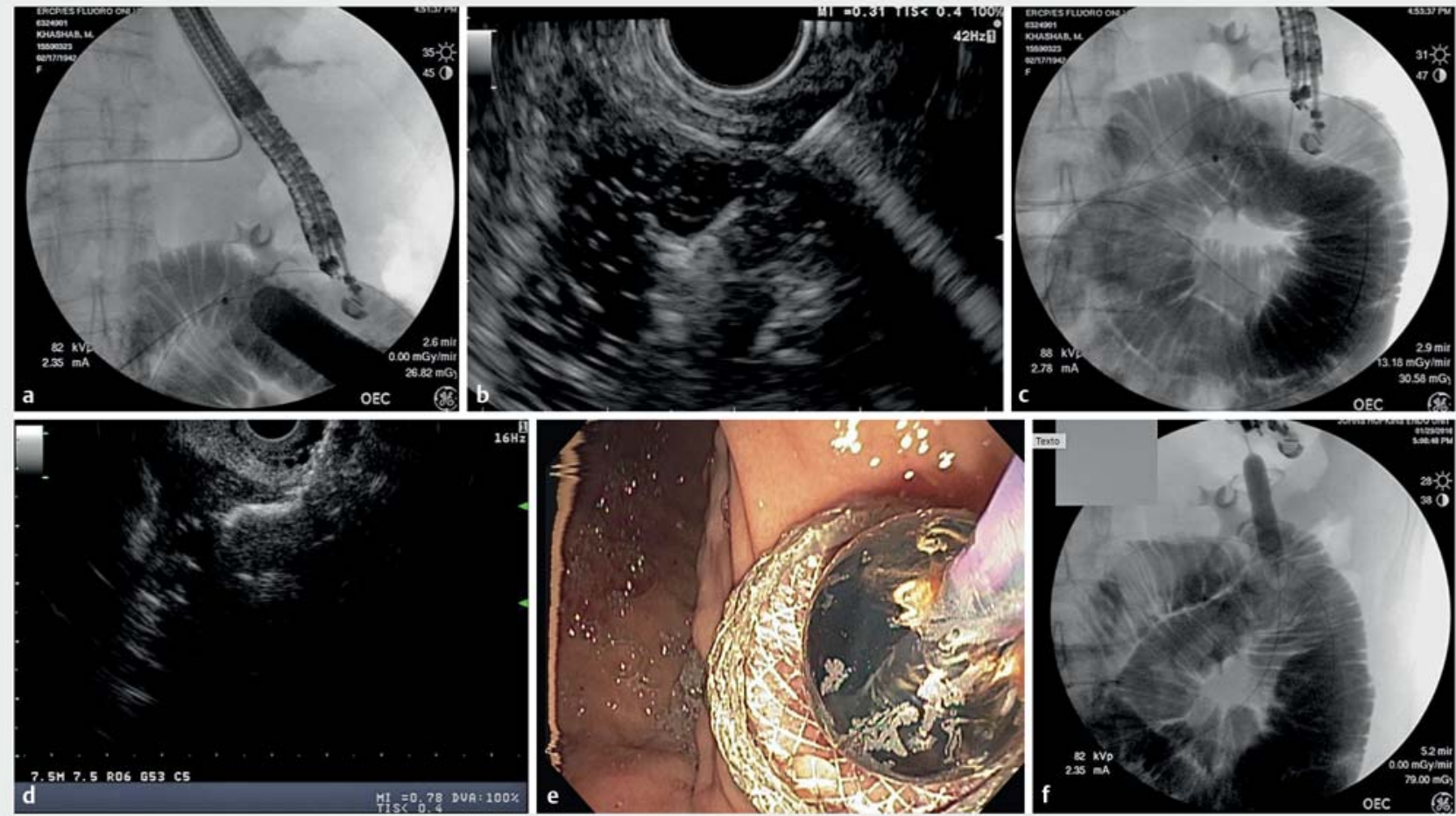

- Fig. 2 EUS-GJ using the balloon-assisted technique in a 74-year-old patient with malignant GOO and biliary obstruction secondary to pancreatic head adenocarcinoma causing duodenal obstruction. A single-balloon enteroscope is advanced into the second duodenum and the stricture is traversed. The small bowel lumen is filled with contrast and normal saline. A 0.035 -inch guidewire is advanced into the small bowel and the enteroscope is removed. A $20 \mathrm{~mm}$ dilating balloon is advanced over the wire to the small bowel distal to the obstruction and was inflated with contrast. a Fluoroscopic visualization of the inflated balloon in the small bowel and the EUS scope in the stomach. $\mathbf{b}$ EUS view of a 19gauge FNA needle in the small bowel loop while puncturing the CRE balloon. $c$ Fluoroscopic view of the FNA needle within the small bowel after deflation of the punctured balloon. $\mathbf{d}$ The cautery enhanced $15 \times 10 \mathrm{~mm}$ LAMS with the distal flange deployed in the small bowel. e After the proximal flange is deployed a $15-\mathrm{mm}$ balloon is advanced and the LAMS dilated. $\mathbf{f}$ Fluoroscopic view of the inflated balloon inside the LAMS.

\section{Discussion}

Enteral stenting is most frequently employed in patients with malignant GOO. Although the procedure is technically successful in the majority of patients, its main shortcoming is recurrent stent obstruction which occurs in a significant proportion of patients who survive longer than 2 to 3 months [13]. The advantage of EUS-GE is its establishment of bypass anastomosis away from the tumor site without risk of tumor ingrowth or overgrowth, which theoretically decreases the risk of recurrent stent obstruction and GOO. One study compared outcomes of EUS-GE and enteral stenting in 30 and 52 patients, respectively. [11] Technical success ( $86.7 \%$ vs $94.2 \%, P=0.2$ ) and clinical success $(83.3 \%$ vs $67.3 \%, P=0.12$ ), respectively, were similar between both groups Symptom recurrence and need for re-intervention, however, was significantly lower in the EUS-GE group (4.0 vs. $28.6 \%, P=0.015$ ) [11].

EUS-BD is an established procedure at centers with expertise in interventional EUS. Multiple studies comparing EUS-BD to percutaneous biliary drainage showed equivalency of both procedures in terms of clinical success [14]. However, EUS-BD is associated with decreased need for reintervention and possibly better quality of life [14]. EUS-CDS or EUS-HGS are the 2 major types of transmural drainage. When EUS-CDS and HGS are compared, EUS-CDS is prone to duodenobiliary reflux, therefore EUS-HGS is preferred in patients with GOO, especially when the duodenal obstruction is at the level of or distal to the papilla [15]. EUS-GBD was recently reported to be useful for acute cholecystitis. Also, a case series reported the feasibility of EUS-GBD for malignant obstructive jaundice when ERCP was unsuccessful or not feasible and EUS-BD was difficult to perform with a technical success, functional success, adverse events, and stent dysfunction of $100 \%, 91.7 \%, 16.7 \%$, and $8.3 \%$, respectively [16].

The concept of double endoscopic bypass was previously described with one case of malignant GOO and biliary obstruction [8]. The current study describes this novel concept. A total of 7 patients underwent successful double bypass, 4 of whom had both procedures done in the same session with $100 \%$ technical and clinical success and ability to tolerate oral intake along with resolution of cholestasis. Although the EUS-BD performed in most patients was a cholecystogastrostomy, which is not the first option, it was performed safely with high clinical success. The decision to perform EUS-GBD was made given that the other 2 approaches were not possible at the moment of the index procedure. Double endoscopic bypass is an appealing procedure for multiple reasons. First, both EUS-GE and EUS-BD can 

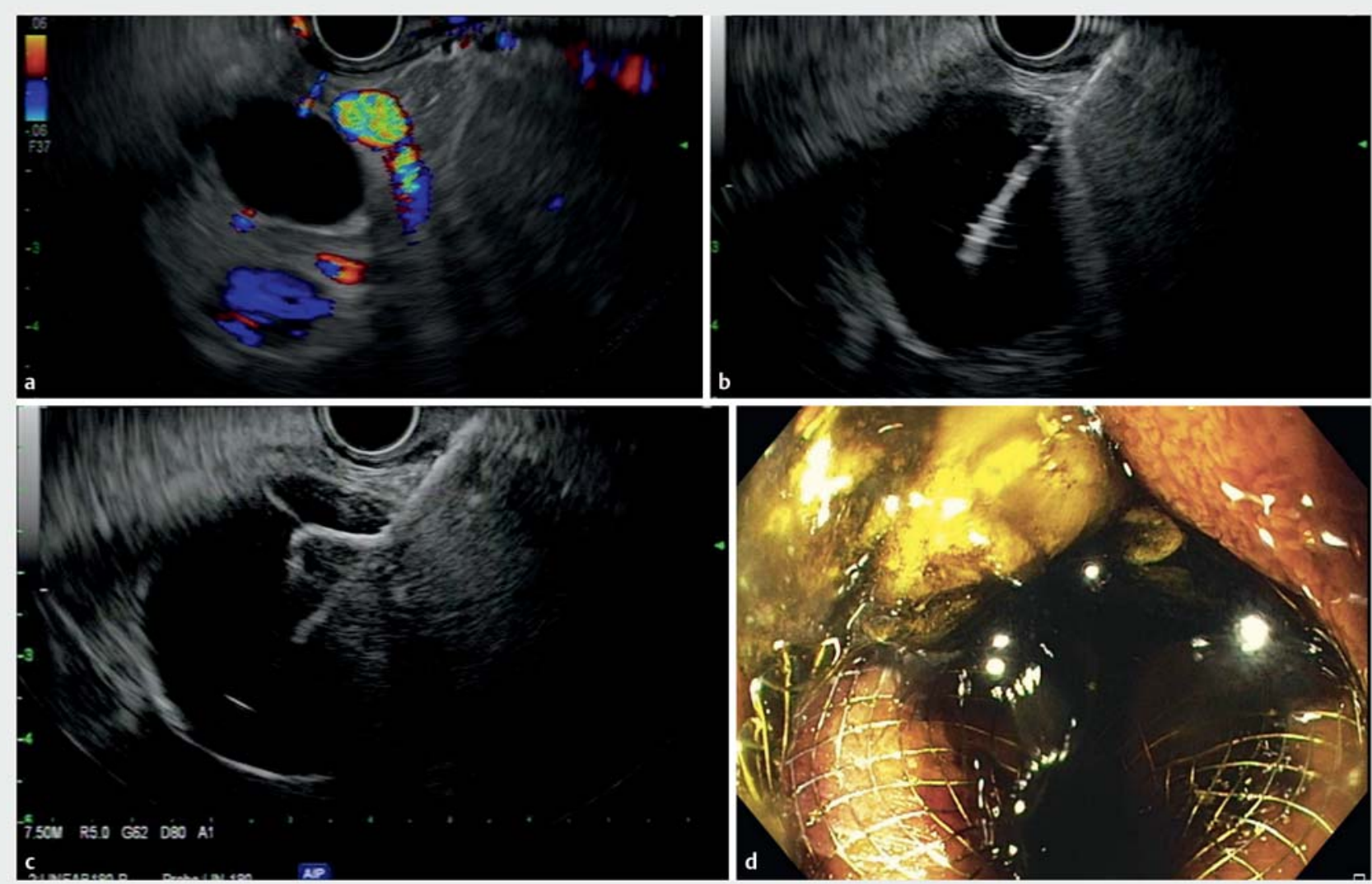

- Fig. 3 EUS-GBD in a 70-year-old patient with malignant GOO and biliary obstruction secondary to pancreatic head adenocarcinoma. The linear echoendoscope is advanced into proximal duodenum. a The CBD was identified but choledochoduodenostomy was not possible due to interposed vessels. $\mathbf{b}$ EUS view of the gallbladder punctured with a 19-gauge FNA needle. $\mathbf{c}$ Distal flange of the LAMS deployed within the gallbladder. $\mathbf{d}$ Endoscopic view of the fully deployed cautery-enhanced LAMS with successful bile drainage.

- Table 1 Patient demographics.

\begin{tabular}{|c|c|c|c|c|c|c|c|c|c|}
\hline Gender & Age & Disease & $\begin{array}{l}\text { Previous inter- } \\
\text { ventions }\end{array}$ & $\begin{array}{l}\text { Obstruction } \\
\text { site }\end{array}$ & $\begin{array}{l}\text { Type of } \\
\text { EUS-EE }\end{array}$ & $\begin{array}{l}\text { Type of } \\
\text { EUS -BD }\end{array}$ & $\begin{array}{l}\text { TB pre/ } \\
\text { post }\end{array}$ & $\begin{array}{l}\text { AP prel } \\
\text { post }\end{array}$ & Re-interventions \\
\hline $\mathrm{F}$ & 79 & PDAC & No & D1/D2 & G] & CDS & $10.8 / 3.9$ & $358 / 438$ & SEMS across LAMS \\
\hline M & 78 & PDAC & No & D1/D2 & G] & HGS & $0.3 / 0.3$ & $266 / 112$ & No \\
\hline M & 70 & PDAC & No & D1/D2 & G] & GBD & $6.9 / 1.1$ & $267 / 157$ & No \\
\hline $\mathrm{F}$ & 44 & PDAC & No & D1/D2 & G] & GBD & $8 / 4.3$ & $300 / 882$ & EUS-HGS \\
\hline M & 60 & PDAC & ERCP with SEMS & D1/D2 & G] & GBD & $4 / 1$ & $290 / 130$ & No \\
\hline $\mathrm{F}$ & 65 & PDAC & No & D1/D2 & G) & GBD & $7.2 / 1.2$ & $622 / 184$ & No \\
\hline $\mathrm{F}$ & 56 & PDAC & No & $\mathrm{D} 1 / \mathrm{D} 2$ & G] & CDS & $16.4 / 1.4$ & $130 / 104$ & No \\
\hline
\end{tabular}

PDAC, pancreatic adenocarcinoma; ERCP, endoscopic retrograde cholangiopancreatography; SEMS, self-expandable metal stent; D1/D2, first/second portion of duodenum; EUS-EE, endoscopic ultrasound enteroenterostomy; G], gastrojejunostomy; EUS-BD, endoscopic ultrasound-guided biliary drainage; CDS, choledochoduodenostomy; HGS, Hepaticogastrostomy; GBD, cholecystogastrostomy

be performed during the same procedure by the same endoscopist. Second, as mentioned previously, bypass stenting carries the potential advantage of longer luminal patency. Double bypass confers this advantage for both luminal patency and biliary patency as food and bile are diverted away from site of obstruction. 
- Table 2 EUS-guided gastroenterostomy.

\begin{tabular}{|c|c|}
\hline & $n=7(\%)$ \\
\hline Sex (female); n (\%) & $4(57.1)$ \\
\hline Age (years); mean \pm SD & $64.6 \pm 12.5$ \\
\hline \multicolumn{2}{|l|}{ Type of malignancy } \\
\hline - Pancreatic head adenocarcinoma; n (\%) & $7(100)$ \\
\hline \multicolumn{2}{|l|}{ Site of obstruction } \\
\hline - D1/D2; n (\%) & $7(100)$ \\
\hline \multicolumn{2}{|l|}{ Type of EUS GE } \\
\hline - G]; n (\%) & $7(100)$ \\
\hline \multicolumn{2}{|l|}{ Technique } \\
\hline - Direct; n (\%) & $5(71.4)$ \\
\hline - Balloon assisted; n (\%) & $2(28.6)$ \\
\hline \multicolumn{2}{|l|}{ Type of LAMS } \\
\hline - Non-cautery enhanced; n (\%) & $2(28.6)$ \\
\hline - Cautery enhanced; n (\%) & $5(71.4)$ \\
\hline \multicolumn{2}{|l|}{ LAMS diameter } \\
\hline - 15 ×10 mm; n (\%) & $7(100)$ \\
\hline Technical success n (\%) & $7(100)$ \\
\hline Clinical success; n (\%) & $7(100)$ \\
\hline \multicolumn{2}{|l|}{ Gooss } \\
\hline - 2 (soft diet); n (\%) & $3(42.9)$ \\
\hline - 4 (full diet); n (\%) & $4(57.1)$ \\
\hline $\mathrm{AE}$ & 0 \\
\hline Re-interventions & 0 \\
\hline Follow up time (days); median [IQR] & $106[66-235]$ \\
\hline \multicolumn{2}{|c|}{$\begin{array}{l}\text { EUS-GE, endoscopic ultrasound-guided gastro-enterostomy; SD, standard } \\
\text { deviation; GJ, gastro-jejunostomy; LAMS, luminal apposing metal stent;, } \\
\text { GOOSS, gastric outlet obstruction scoring system; AE, adverse events; IQR, } \\
\text { interquartile range }\end{array}$} \\
\hline
\end{tabular}

\section{Conclusion}

This is a small case series from tertiary centers and therefore results cannot be generalized. Prospective comparative studies are needed to establish the superiority of double endoscopic bypass over standard techniques (i.e. duodenal stenting and ERCP). It is crucial to mention that ERCP is technically challenging in patients with existing duodenal stents and fails in twothirds of patients, even in experienced hands [2]. Recent availability of LAMS has rendered EUS-GE feasible. Future availability of larger LAMS (e.g. $20 \mathrm{~mm}$ in diameter) is expected to improve palliation of GOO symptoms. In addition, future availability of biliary LAMS ( $6 \mathrm{~mm}$ and $8 \mathrm{~mm}$ in diameter) in the United States is also expected to render EUS-BD simpler, and possibly safer.

In conclusion, double endoscopic bypass appears to be feasible and effective when performed by experienced operators.
- Table 3 EUS- guided biliary drainage.

\begin{tabular}{|c|c|}
\hline & $n=7$ \\
\hline Sex (female); n (\%) & $4(57.1)$ \\
\hline Age (years); mean \pm SD & $64.6 \pm 12.5$ \\
\hline \multicolumn{2}{|l|}{ Type EUS guided biliary drainage } \\
\hline - EUS-CDS; n (\%) & $2(28.6)$ \\
\hline - EUS-HGS; n (\%) & $1(14.3)$ \\
\hline - EUS-GBD; n (\%) & $4(57.1)$ \\
\hline \multicolumn{2}{|l|}{ Type and diameter of stent } \\
\hline - Non-cautery enhanced LAMS/10 × 10 mm; n (\%) & $1(14.3)$ \\
\hline - Cautery-enhanced LAMS/10×10 mm; n (\%) & $3(42.9)$ \\
\hline - Cautery-enhanced LAMS/10×15 mm; n (\%) & $2(28.6)$ \\
\hline - FCSEMS/10 mm × 80 mm; n (\%) & $1(14.3)$ \\
\hline Technical success; $\mathrm{n}(\%)$ & $7(100)$ \\
\hline Clinical success; n (\%) & $6(85.7)$ \\
\hline - Total bilirubin pre procedure; mean \pm SD & $7.7 \pm 5.1$ \\
\hline - Total bilirubin post procedure; mean \pm SD & $1.9 \pm 1.6$ \\
\hline - Alkaline phosphatase pre procedure; mean \pm SD & $319 \pm 150.4$ \\
\hline - Alkaline phosphatase post procedure; mean \pm SD & $286.7 \pm 286.7$ \\
\hline $\mathrm{AE}$ & 0 \\
\hline Re-interventions; n (\%) & $2(28.6)$ \\
\hline $\begin{array}{l}\text { - Cystic duct obstruction/EUS-HGS with } \\
10 \times 80 \mathrm{~mm} \text { FCSEMS; } \mathrm{n}(\%)\end{array}$ & $1(50)$ \\
\hline $\begin{array}{l}\text { - } 10 \mathrm{~mm} \text { CDS LAMS clogged/10 } \times 40 \mathrm{~mm} \text { FCSEMS } \\
\text { through the LAMS; } \mathrm{n}(\%)\end{array}$ & $1(50)$ \\
\hline
\end{tabular}

Follow up time (days); median [IQR]

$106[67-229]$

EUS-BD, endoscopic ultrasound-guided biliary drainage; SD, standard deviation; EUS-CDS, endoscopic ultrasound- choledochoduodenostomy; EUSHGS, endoscopic ultrasound-hepaticogastrostomy; EUS-GBD, endoscopic ultrasound gallbladder drainage; LAMS, luminal apposing metal stent; FCSEMS, fully covered self-expandable metal stent; AE, adverse events; IQR, interquartile range

Studies comparing this novel concept to existing techniques are warranted. Further refinement in stent technology is expected to render the procedure more efficient and safer.

\section{Competing interests}

Dr. Baron is a consultant for Boston Scientific and Olympus. Dr. Irani is a consultant for Boston Scientific and Gore. Dr. Khashab is a consultant for Boston Scientific and Olympus. 


\section{References}

[1] Lillemoe KD, Cameron JL, Hardacre JM et al. Is prophylactic gastrojejunostomy indicated for unresectable periampullary cancer? A prospective randomized trial Ann Surg 1999; 230: 322 - 328; discussion 328-330

[2] Khashab MA, Valeshabad AK, Leung W et al. Multicenter experience with performance of ERCP in patients with an indwelling duodenal stent. Endoscopy 2014; 46: $252-255$

[3] Khashab MA, Fujii LL, Baron TH et al. EUS-guided biliary drainage for patients with malignant biliary obstruction with an indwelling duodenal stent (with videos). Gastrointest Endosc 2012; 76: 209-213

[4] Itoi T, Baron TH, Khashab MA et al. Technical review of endoscopic ultrasonography-guided gastroenterostomy in 2017. Dig Endosc 2016; 29: 495-502

[5] Khashab MA, Baron TH, Binmoeller KF et al. EUS-guided gastroenterostomy: a new promising technique in evolution. Gastrointest Endosc 2015; 81: $1234-1236$

[6] Khashab MA, Kumbhari V, Grimm IS et al. EUS-guided gastroenterostomy: the first U.S. clinical experience (with video). Gastrointest Endosc 2015; 82: 932 - 938

[7] Khashab MA, Levy M], Itoi T et al. EUS-guided biliary drainage. Gastrointest Endosc 2015; 82: $993-1001$

[8] Khashab MA, El Zein M, Ngamruengphong S et al. Double endoscopic bypass by using lumen-apposing stents (with videos). Gastrointest Endosc 2016; 83: 435-439
[9] Adler DG, Baron TH. Endoscopic palliation of malignant gastric outlet obstruction using self-expanding metal stents: experience in $36 \mathrm{pa}-$ tients. Am J Gastroenterol 2002; 97: 72 - 78

[10] Cotton PB, Eisen GM, Aabakken L et al. A lexicon for endoscopic adverse events: report of an ASGE workshop. Gastrointest Endosc 2010; $71: 446-454$

[11] Chen YI, Itoi T, Baron TH et al. EUS-guided gastroenterostomy is comparable to enteral stenting with fewer re-interventions in malignant gastric outlet obstruction. Surg Endosc 2016: 1-7

[12] Khashab MA, Valeshabad AK, Modayil R et al. EUS-guided biliary drainage by using a standardized approach for malignant biliary obstruction: rendezvous versus direct transluminal techniques (with videos). Gastrointest Endosc 2013; 78: $734-741$

[13] Khashab M, Alawad AS, Shin EJ et al. Enteral stenting versus gastrojejunostomy for palliation of malignant gastric outlet obstruction. Surg Endosc 2013; 27: 2068-2075

[14] Khashab MA, Valeshabad AK, Afghani E et al. A comparative evaluation of EUS-guided biliary drainage and percutaneous drainage in patients with distal malignant biliary obstruction and failed ERCP. Dig Dis Sci 2015; 60: 557-565

[15] Nakai $\mathrm{Y}$, Hamada $\mathrm{T}$, Isayama $\mathrm{H}$ et al. Endoscopic management of combined malignant biliary and gastric outlet obstruction. Dig Endosc. 2017 Jan29: $16-25$

[16] Imai H, Kitano M, Omoto S et al. EUS-guided gallbladder drainage for rescue treatment of malignant distal biliary obstruction after unsuccessful ERCP. Gastrointest Endosc 2016; 84: 147-151 